\title{
Performance of general circulation models in southeastern South America
}

\author{
Raúl Hofstadter ${ }^{1, *}$, Mario Bidegain ${ }^{2}$ \\ ${ }^{1}$ Estudio País sobre Cambio Climático, Comisión Nacional sobre Cambio Global, Ciudadela 1414, piso 6, \\ 11100 Montevideo, Uruguay \\ ${ }^{2}$ Dirección Nacional de Meteorología, Javier Barrios Amorín 1488, 11200 Montevideo, Uruguay
}

\begin{abstract}
Outputs from 5 general circulation models (GCMs) were analyzed in order to evaluate their performance for estimating future climate conditions in the temperate zone of southeastern South America $\left(24^{\circ}\right.$ to $38^{\circ} \mathrm{S}$ and $50^{\circ}$ to $\left.65^{\circ} \mathrm{W}\right)$. The GCMs analyzed were: GISS (Goddard Institute for Space Science), GFDL-R30 and GFDL $1 \%$ (Geophysical Fluid Dynamics Laboratory), UKMO (United Kingdom Meteorological Office), and CCCM (Canadian Climate Center Model). The variables under study were mean monthly temperature and mean daily precipitation. The degree to which the models represent current climate was estimated by comparing model outputs with observed climate values for the 1951 to 1970 period by means of a correlation analysis. The temperature values estimated by the models showed a good fit with the observed values. However, fitting of precipitation values was not statistically significant. This study was carried out within the framework of the Uruguay Climate Change Country Study as a basis for assessing the impact of climate change on the agricultural sector.
\end{abstract}

KEY WORDS: General circulation models · Climate change Climate scenarios · Climate simulation

\section{INTRODUCTION}

Since the 19th century, emissions of carbon dioxide $\left(\mathrm{CO}_{2}\right)$ and other greenhouse gases to the atmosphere have increased as a result of industrial and agricultural activities. It is foreseen that the steady increase in the atmospheric concentration of greenhouse gases will affect climate, although there are uncertainties as to the magnitude of such changes.

An increase in global surface temperature is projected by general circulation models (GCMs) as one of the main effects of anthropogenic greenhouse gas emissions. The rise in mean global temperature is estimated to be 1.5 to $4.5^{\circ} \mathrm{C}$ within the next $100 \mathrm{yr}$, at a rate of approximately 0.2 to $0.5^{\circ} \mathrm{C}$ per decade (IPCC 1990).

GCMs are mathematical representations of the atmosphere, oceans and ice movements and of their interactions, which include a wide range of physical processes that characterize climate. These models pro-

•E-mail: mbidegai@cncg.gub.uy vide simulations of current and future climate conditions, and allow for the quantification of the effects of increased greenhouse gas concentrations on climate.

Models simulate the formation of clouds, solar radiation, distribution and amount of precipitation, wind direction and intensity, temperature at the surface and at selected levels in the atmosphere, and surface pressure. In addition to atmospheric processes, changes in oceanic circulation, polar ice caps and land cover are also considered by such models.

Even though a large number of variables are handled by climate models, an accurate description of the climate system has not been achieved as yet due to the long processing time required. The low resolution of the models has only recently been improved.

The GCMs used during the 1980s had a horizontal resolution of 600 to $950 \mathrm{~km}$, while that of some models currently available is of $350 \mathrm{~km}$ (Jenne 1992).

Outputs from 5 GCMs were analyzed during the present study. Model outputs were compared with observed regional climate for the 1951 to 1970 period. 
Table 1 Resolution and temperature sensitivity of the different GCMs used

\begin{tabular}{|lcc|}
\hline Model & $\begin{array}{c}\text { Resolution } \\
(\text { lat. } \times \text { long. })\end{array}$ & $\begin{array}{c}\text { Sensitivity } \\
\left({ }^{\circ} \mathrm{C} \text { for } 2 \times \mathrm{CO}_{2}\right)\end{array}$ \\
\hline GISS & $7.83^{\circ} \times 10.0^{\circ}$ & 4.2 \\
GFDL-R30 & $2.22^{\circ} \times 3.75^{\circ}$ & 3.2 \\
GFDL $1 \%$ & $4.44^{\circ} \times 7.50^{\circ}$ & - \\
UKMO & $2.50^{\circ} \times 3.75^{\circ}$ & 3.5 \\
CCCM & $3.75^{\circ} \times 3.75^{\circ}$ & 3.5 \\
\hline
\end{tabular}

The degree to which simulated mean monthly temperature and mean daily precipitation values replicated observed data was estimated. The study area included Uruguay, the southern part of Brazil and the eastern part of Argentina.

This analysis, performed within the framework of the Uruguay Climate Change Country Study, was used as a basis for assessing the impact of climate change on the agricultural sector.

\section{METHODOLOGY}

The GCMs analyzed were provided by NCAR (National Center for Atmospheric Research, Boulder, CO, USA) to the Uruguay Climate Change Country Study through the U.S. Country Studies Program. They include the GISS (Goddard Institute for Space Science), the GFDL-R30 and GFDL 1\% (Geophysical Fluid Dynamics Laboratory), the UKMO (United Kingdom Meteorological Office), and the CCCM (Canadian Climate Centre Model).

The horizontal resolution and sensitivity of each model is indicated in Table 1.

The GISS model (Hansen et al. 1983, 1988) has a diurnal cycle, with low horizontal resolution, 9 levels in the atmosphere and 13 levels in the ocean. It has a $Q$ flux energy exchange system to improve simulation of the interaction between the ocean and sea ice. Ocean water temperatures and ice cover are computed on the basis of an hour-byhour energy exchange with the atmosphere, the ocean heat transport and the ocean surface-layer heat capacity. It uses the so-called slab ocean, a simple ocean not more than $65 \mathrm{~m}$ deep.

The GFDL-R30 model (Stouffer et al. 1989) has a high horizontal resolution and
9 levels in the atmosphere. It is a 30-wave spectral model, which does not have a diurnal cycle.

The GFDL $1 \%$ model (Manabe et al. 1991) is a transient model. It has a low horizontal resolution. The ocean has a better resolution in longitude than in latitude. The model has 9 levels in the atmosphere and 12 in the ocean; the bottom ocean level is $5 \mathrm{~km}$ deep. The ocean dynamics are better represented in this model than in the GFDL-R30 model.

The UKMO model (Wilson \& Mitchell 1987) has high horizontal resolution, 11 levels in the atmosphere plus the surface, and a diurnal cycle. The model allows for the simulation of cloud water content and the development of convective clouds. It has a $Q$ flux slab ocean.

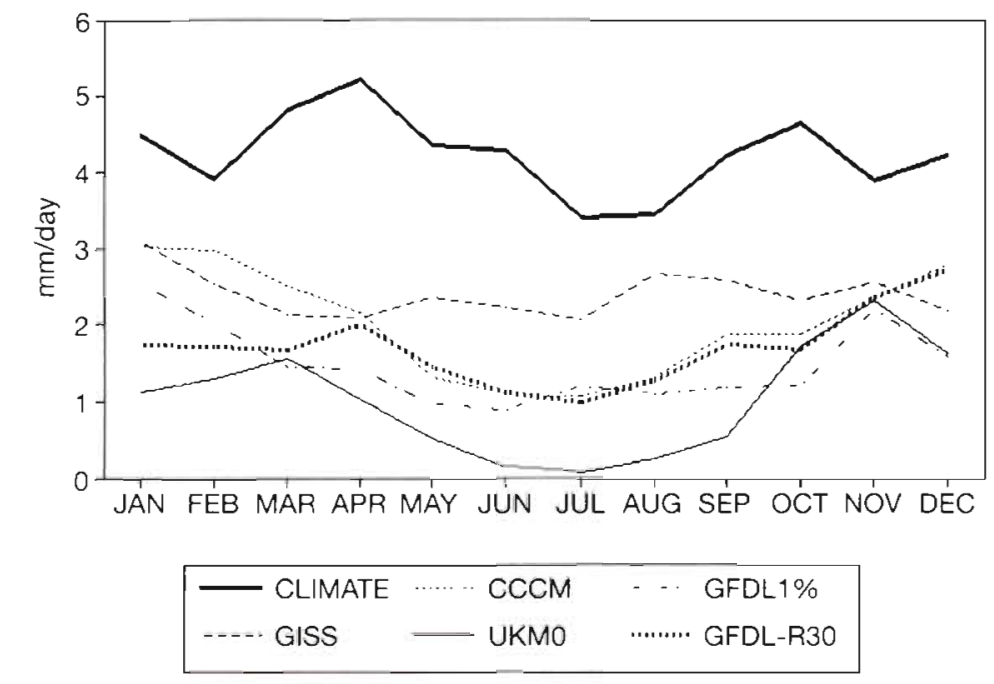

Fig. 1 GCM-generated precipitation data and observed values at $30^{\circ} \mathrm{S}$ latitude. $55^{\circ} \mathrm{W}$ longitude, for the 1951 to 1970 period

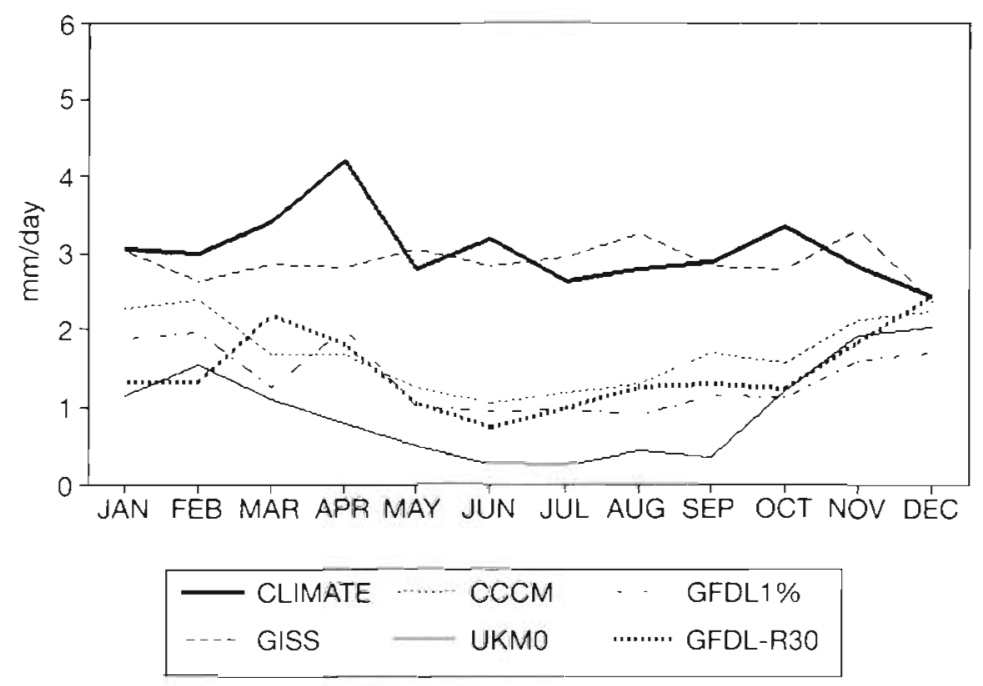

Fig. 2. GCM-generated precipitation data and observed values at $35^{\circ} \mathrm{S}$ latitude, $55^{\circ} \mathrm{W}$ longitude, for the 1951 to 1970 period 
The CCCM is a high resolution model. It has 10 levels in the atmosphere and a 50-mdeep slab ocean and uses a $Q$ flux system. It has a relative humidity scheme for development of clouds and a diurnal cycle.

Climate data from 1951 to 1970 provided as grid point values by NCAR, were used. The temperature and precipitation data were obtained from Taljaard et al. (1969) and Schutz \& Gates $(1971,1972)$. These values were compared and completed with available information for the same period collected at the 'Dirección Nacional de Meteorología' weather stations (DNM 1971). The selected study period was considered not to be affected by climate change.

The model outputs were displayed and analyzed as grid values using the GrADS program (Gridded Analysis and Display System) produced at the University of Maryland (Kinter \& Doty 1994). Global grid fields may be displayed and then a specific region selected, with varying spatial resolution.

A correlation analysis was carried out for estimating the consistency between the observed and simulated temperature and precipitation data.

\section{RESULTS AND DISCUSSION}

Figs. 1 \& 2 display the precipitation values generated with the GCMs for $30^{\circ}$ and $35^{\circ} \mathrm{S}$ latitudes and $55^{\circ} \mathrm{W}$ longitude, as well as the observed values, for the 1951 to 1970 period.

Figs. $3 \& 4$ display the temperature values generated by the GCMs for $30^{\circ}$ and $35^{\circ} \mathrm{S}$ latitudes, $55^{\circ} \mathrm{W}$ longitude, as well as the observed data, for the 1951 to 1970 period.

The temperature values generated by the models are consistent with the observed values. However, simulated precipitation values are erratic and in some cases much lower than the observed value.

The spatial distribution of simulated mean annual temperature and mean daily precipitation is shown in Figs. 5 \& 6 respectively. As mentioned above, the temperature model outputs give an accurate representation of the observed temperature pattern, while precipitation outputs differ from the observed data both in magnitude and spatial distribution.

Values of the linear correlation coefficients ( $r$ ) between estimated and observed values for temperature and precipitation are presented in Table 2 . The coefficients are highly significant with regard to tem-
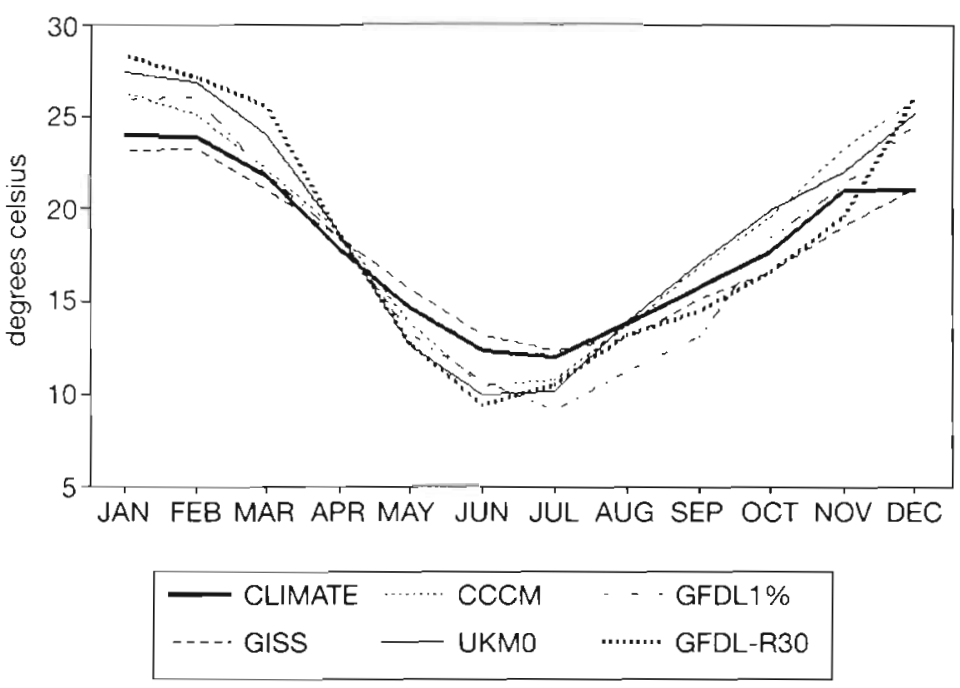

Fig. 3. GCM-generated temperature data and observed values at $30^{\circ} \mathrm{S}$ latitude, $55^{\circ} \mathrm{W}$ longitude, for the 1951 to 1970 period
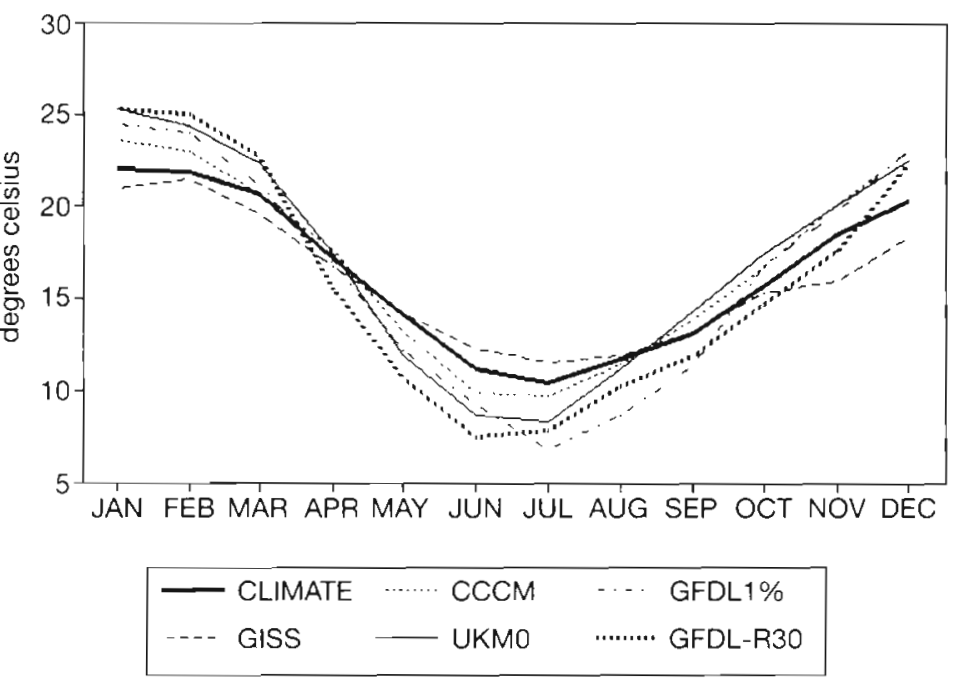

Fig. 4. GCM-generated temperature data and observed values at $35^{\circ} \mathrm{S}$ latitude, $55^{\circ} \mathrm{W}$ longitude, for the 1951 to 1970 period

perature for all models, but not significant for precipitation.

The results of this study are consistent with findings from studies carried out in other regions of Latin America (M. Núñez pers. comm., C. Conde pers. comm.) in that the different models provide a much more accurate simulation of temperature than of precipitation patterns. This is due to the fact that temperature is, in the long run, strongly influenced by the global energy balance and is therefore better simulated by the models than precipitation, which is determined by smallerscale factors (regional to local) not handled by the models. 

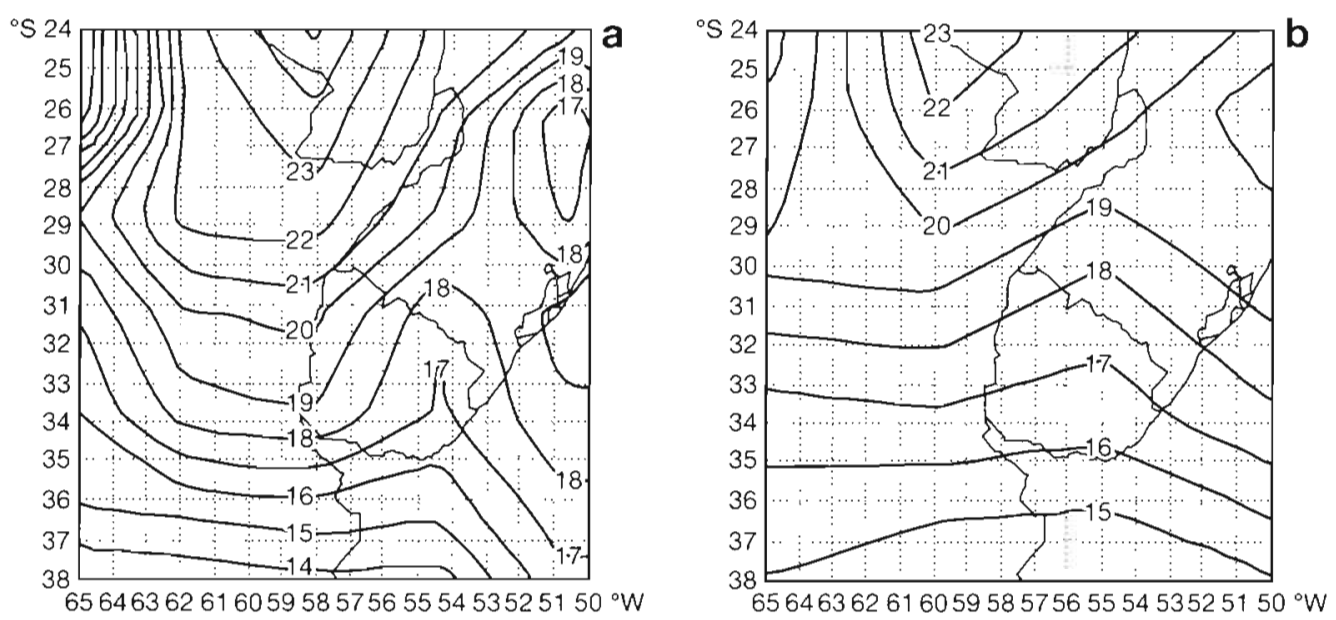

Fig. 5. Comparison between (a) the distribution of mean annual temperature values estimated by the UKMO model and (b) the observed temperature pattern. Values in ${ }^{\circ} \mathrm{C}$
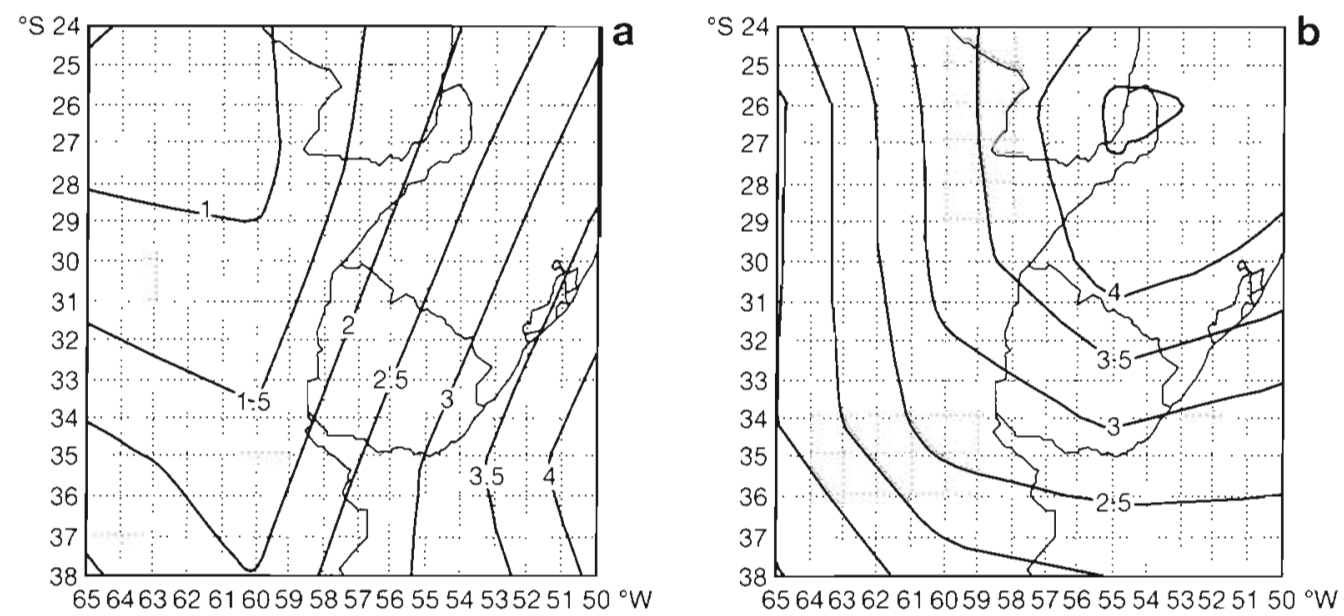

Fig. 6. Comparison between (a) the distribution of mean daily precipitation values estimated by the GISS model and (b) the observed precipitation pattern. Values in $\mathrm{mm}$

\section{CONCLUSIONS}

GCMs accurately simulate temperature for the study region. This is reflected by the highly significant correlation coefficients obtained between the observed and the simulated values. Although the outputs of different models were not compared, there seem to be no significant differences among them. In spite of this, all models tend to overestimate the amplitude of the annual temperature cycle. The climate conditions in the study region are best represented by the UKMO model (Fig. 5)

The reliability of precipitation simulations for the region is much lower than in the case of temperature. This is due, firstly, to the fact that precipitation is indirectly affected by a large variety of processes, many of which are not resolved by the model grid. Modelling thus becomes a much more complex process. Secondly, precipitation changes are relatively minor compared to natural global variability, and are therefore much more

Table 2. Correlations between simulated and observed temperature for the 1951 to 1970 period. * Significant values $(p<$ $0.01)$

\begin{tabular}{|lcccc|}
\hline \multirow{2}{*}{ Model } & \multicolumn{2}{c}{ Temperature } & \multicolumn{2}{c|}{ Precipitation } \\
& $30^{\circ}$ S lat. & $34^{\circ}$ S lat. & \multicolumn{3}{c}{$30^{\circ}$ S lat. } & $34^{\circ}$ S lat. \\
\hline GISS & $0.98 \cdots$ & $0.98 \cdots$ & -0.23 & -0.30 \\
GFDL-R30 & $0.97 \cdots$ & $0.98 \cdots$ & 0.31 & 0.08 \\
GFDL $1 \%$ & $0.98 \cdots$ & $0.99 \cdots$ & 0.03 & 0.32 \\
UKMO & $0.98 \cdots$ & $0.98 \cdots$ & 0.33 & -0.13 \\
CCCM & $0.97 \cdots$ & $0.98 \cdots$ & 0.32 & -0.83 \\
Observed & 1.00 & 1.00 & 1.00 & 1.00 \\
\hline
\end{tabular}


difficult to detect during a relatively short monitoring period (IPCC 1990). Model simulations of precipitation are more accurate for temperate regions than for high latitude zones. The frontal rains are better simulated by the models than the scattered precipitation associated with mesoscale convective processes. The latter are not considered by any of the models.

It is concluded that temperature can be accurately simulated by any of the models under consideration. In contrast, models are not useful when the aim is to estimate precipitation values for the region. The application of methods such as 'Perfect Prog' or downscaling is likely to improve precipitation simulations.

\section{LITERATURE CITED}

DNM (Dirección Nacional de Meteorología) (1971) Estadísticas climatológicas 1946-1970. Dirección de Climatología y Documentación, Montevideo

Hansen, J, Fung I, Lacis A, Rind D, Lebedeff S, Ruedy R, Russel G, Stone P (1988) Global climate changes as forecast by Goddard Institute for Space Science three-dimensional model. J Geophys Res 93:9341-9364

Hansen J, Russell G, Rind D, Stone P, Lacis A, Lebedeff S, Ruedy R, Travis L (1983) Efficient three-dimensional global models for climate studies: Models I and II. Mon Weather Rev III:609-662
IPCC (1990) Climate change: the IPCC scientific assessment. Houghton GJ, Jenkins JJ, Ephraums JJ (eds). Cambridge University Press, Cambridge

Jenne RL (1992) Climate model description and impact on terrestrial climate. In: Majumdar et al. (eds) Global climate change: implications, challenges and mitigation. NCAR, Boulder, $\mathrm{CO}$

Kinter J, Doty B (1994) GrADS (Gridded Analysis and Display System). University of Maryland, Baltimore

Manabe S, Stouffer RJ, Spelman MJ, Bryan K (1991) Transient response of a coupled ocean-atmosphere model to gradual changes of atmospheric carbon dioxide. Part I: Annual mean response. J Clim 4:785-818

Schutz C, Gates WL (1971) Global climate data for surface, $800 \mathrm{mb}, 400 \mathrm{mb}$ : January. Report R-915-ARPA, Advanced Research Projects Agency, Rand Corporation, Santa Monica, CA

Schutz C, Gates WL (1972) Global climate data for surface, 800 mb, 400 mb: July. Report R-1029-ARPA, Advanced Research Projects Agency, Rand Corporation, Santa Monica, CA

Stouffer RJ, Manabe S, Bryan K (1989) Interhemispheric asymmetry in climate response to a gradual increase in the atmospheric $\mathrm{CO}_{2}$. Nature 342:660-662

Taljaard JJ, Van Loon H, Crutcher HL, Jenne RL (1969) Climate of the upper air. Southern Hemisphere 1 Temperatures, dewpoints, and heights at selected pressure levels. NAVAIR 50-1C-55, Chief of Naval Operations, Washington, DC, p 135

Wilson CA, Mitchell JFB (1987) A doubled $\mathrm{CO}_{2}$ climate sensivity experiment with a global climate model including a single ocean. J Geophys Res 92:315-343 